\title{
Changes in Transfusion Practice in Children and Adolescents over Time
}

\author{
Florian Piekarski $^{a} \quad$ Andrea Steinbicker $^{\mathrm{b}} \quad$ Kai Zacharowski $^{\mathrm{a}} \quad$ Patrick Meybohm $^{\mathrm{c}}$ \\ a Department of Anaesthesiology, Intensive Care Medicine and Pain Therapy, University Hospital Frankfurt,

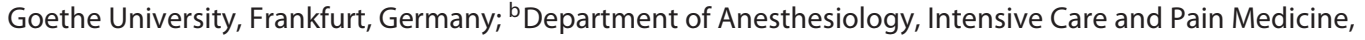 \\ University Hospital Muenster, University of Münster, Münster, Germany; ${ }^{C}$ Department of Anaesthesia and Critical \\ Care, University Hospitals of Würzburg, University of Würzburg, Würzburg, Germany
}

\section{Keywords}

Transfusion · Children · Pediatric patients · Patient blood management

\begin{abstract}
Introduction: In recent years, resource-saving handling of allogeneic blood products and a reduction of transfusion rates in adults has been observed. However, comparable published national data for transfusion practices in pediatric patients are currently not available. In this study, the transfusion rates for children and adolescents were analyzed based on data from the Federal Statistical Office of Germany during the past 2 decades. Methods: Data were queried via the database of the Federal Statistical Office (Destasis). The period covered was from 2005 to 2018, and those in the sample group were children and adolescents aged $0-17$ years receiving inpatient care. Operation and procedure codes (OPS) for transfusions, procedures, or interventions with increased transfusion risk were queried and evaluated in detail. Results: In Germany, $0.9 \%$ of the children and adolescents treated in hospital received a transfusion in 2018. A reduction in transfusion rates from $1.02 \%$ (2005) to $0.9 \%$ (2018) was observed for the total collective of children and adolescents receiving inpatient care. Increases in transfusion rates were recorded for 1- to 4(1.41-1.45\%) and 5- to 10-year-olds (1.24-1.33\%). Children under 1 year of age were most frequently transfused (in $2018,40.2 \%$ of the children were cared for in hospital). Transfusion-associated procedures such as chemotherapy or machine ventilation and respiratory support for new-
\end{abstract}

borns and infants are on the rise. Conclusion: Transfusion rates are declining in children and adolescents, but the reasons for increases in transfusion rates in other groups are unclear. Prospective studies to evaluate transfusion rates and triggers in children are urgently needed.

(c) 2020 S. Karger AG, Basel

\section{Introduction}

Allogeneic blood transfusions can be a life-saving treatment option for neonates and children with severe bleeding or severe anemia. The blood bank network in Germany guarantees an adequate supply of blood products $24 \mathrm{~h}$ a day. Germany tops the list in an international comparison of such supplies, with a consumption of 38.9 units of blood per 1,000 inhabitants [1]. In recent years, however, a continuous decline in adult consumption has been observed [1]. Specific data for Germany on the development of transfusion rates in children and adolescents aged 0-17 years are currently not available.

Transfusions are also known to be associated with multiple risks in children (including allergic reactions, transfusion-associated lung injury (TRALI), immunological risks, hepatitis B and C, and HIV infection) [2-4]. The risk for the occurrence of an adverse event such as a mistransfusion after allogeneic blood transfusion is 1.3 times higher in children 1 year and older and 2.8 times higher in newborns (excluding premature infants) compared with adults $[3,5]$. Other data indicate 6.2 responses per 1,000 transfusions within the pediatric (age $<21$ ) population [6]. 


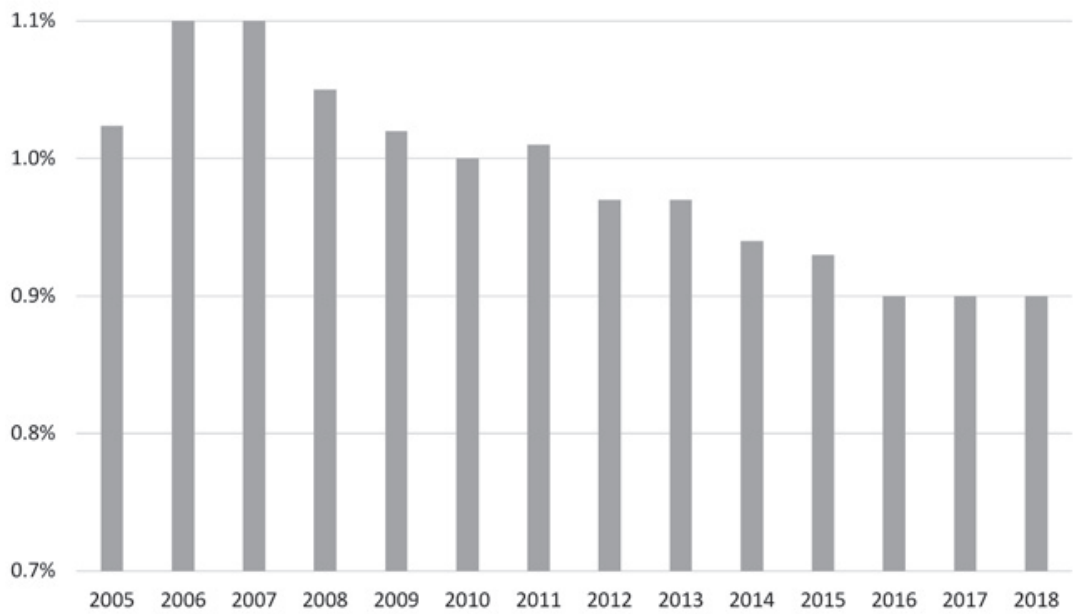

Fig. 1. Development of transfusion rates for children in inpatient care in Germany.

Statistically higher rates of allergic reactions, febrile nonhemolytic reactions, and acute hemolytic reactions have been shown in children than in adults [7]. A comprehensive risk-benefit assessment is therefore necessary when deciding on a transfusion. Recommendations for transfusion in children and adolescents are given primarily for medical reasons [5]. Data from a 2008 study in the United Kingdom show that hematological and oncological patients with the leading diagnoses of acute leukemia made up the majority of transfused children that year [5].

Using current data from the Federal Statistical Office, this article presents the development of transfusion rates in children and adolescents in Germany and shows the development of transfusion-associated procedures.

We hypothesize that the transfusion rates for children in Germany are declining, comparably to the development of these rates in adults.

\section{Materials and Methods}

The hypothesis that the transfusion rates for children in Germany have been declining in recent years was examined on the basis of central data from the Federal Statistical Office. The primary endpoint was the transfusion rate in children in Germany, and the secondary endpoint was the development of case numbers in disciplines with increased transfusion rates.

The data were queried via the online database of the Federal Statistical Office (Destasis). The available period was recorded for the years 2005 to 2018, based on the diagnosis-related group (DRG) statistics. Detailed DRG data are not available before 2005, as this system was only then introduced throughout the country. The most recent available data are from 2018.

The operation and procedure codes (OPS) required for this and transmitted via the DRG billing system can be retrieved from the
Federal Statistical Office [8]. Their use for statistical analysis has already been demonstrated in other questions from our research group $[9,10]$. Included in this study were patients aged $0-17$ years who had received full inpatient care. OPS is the official classification for coding surgeries, procedures, and general medical measures and is the official classification for service records of German hospitals [11].

The first digit of the operation and procedure code provides information on the type of measure; e.g., " 5 " indicates operation or " 8 " indicates a nonoperative therapeutic measure. Transfusions are coded under OPS $8-800$. Supplementary digits in the 5 th position; e.g., 8-800.6 d, give information about the amount and type of blood product applied. In the DRG statistics, OPS are stored up to the 4 th digit, so a detailed analysis of the number and type of blood products (whole blood, erythrocyte, or thrombocyte concentrates) is not possible. This database extends to hospitals that are subject to DRG billing.

To illustrate the simultaneous development of OPS with a focus on transfusion, several subgroup analyses were conducted. Since transfusions in children are largely indicated for medical or surgical reasons but especially for the age groups $0-4$ and $15-19$ years [12], the following OPS were analyzed exemplarily: transfusion of whole blood, red cell concentrate, and platelet concentrate (OPS 8-800); surgery (OPS 5-01 to 5-99); cytostatic chemotherapy, immunotherapy and antiretroviral therapy (OPS 8-541 to 549); transplantation of hematopoietic stem cells (OPS 5-411); and machine ventilation and respiratory support for newborns and infants (OPS 711). Data on transfusion rates of the exemplary subgroups are not yet available. The selection was based on internal quality assurance data. It was not possible to query the above-mentioned OPSs in combination with each other, as hospitals do not report individual cases but only the respective figures per OPS. Therefore, the respective OPSs were calculated as percentages of the total number of children treated in hospital. Sub-analyses were also carried out for the age groups ( $<1$ year, $1-4,5-10,10-15$, and 15-17 years), distributed according to federal state and gender. After this, the relation of OPS 5-01 to 5-99 and OPS 8-800 to the number of inhabitants aged $0-17$ years in the individual federal states was calculated as a percentage. 
Fig. 2. Development of transfusion rates for children in inpatient care in Germany by age group.

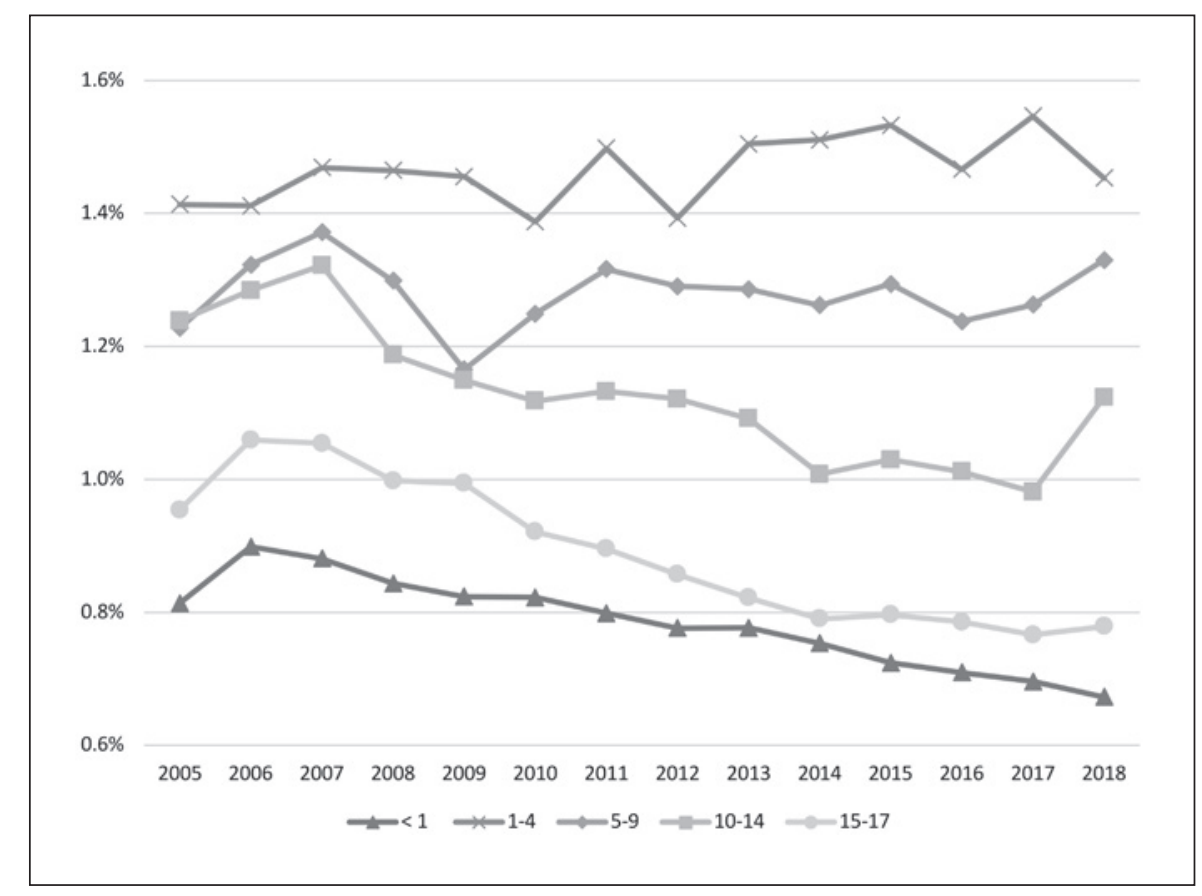

For statistical analysis, descriptive methods were performed using Microsoft ${ }^{\circledR}$ Office Excel, Excel for Mac version 16.3, Microsoft Corporation, Redmond, WA, USA, and IBM ${ }^{\circledR}$ SPSS $^{\circledR}$ Statistics, version 26, IBM ${ }^{\circledR}$, Armonk, NY, USA. Results were presented using absolute and relative frequencies, and percentage trends were calculated.

\section{Results}

\section{Transfusions}

In Germany, $0.9 \%$ of the children and adolescents treated in hospital received a transfusion during the period studied. An absolute increase of $+10.8 \%$ in coded transfusions of whole blood, erythrocyte concentrates, and thrombocyte concentrates has been recorded since the years $2005(n=29,998)$ and $2018(n=33,248)$. However, in relation to the total number of children aged 0-17 years in inpatient care, there has been a relative decrease in transfusion rates, from $1.02 \%$ (2005) to $0.9 \%$ (2018) (Fig. 1). A percentage increase was recorded for the subgroups aged $1-4$ years $(1.41-1.45 \%)$ and 5-9 years (1.24$1.33 \%$ ) (Fig. 2). The distribution of transfusion rates within the age groups was the same over the years covered. Thus, children under 1 year of age were transfused most frequently compared with other age groups: in 2005, $37.5 \%(11,254$ out of 29,988$)$ and in $2018,40.2 \%(13,378$ out of 33,248$)$ of the transfused children were $<1$ year old. Children aged 0-17 years were most frequently transfused in the federal state of Niedersachsen, at a rate of $1.65 \%$. In contrast, the proportion was lowest in Brandenburg, with $0.44 \%$ (Fig. 3). 


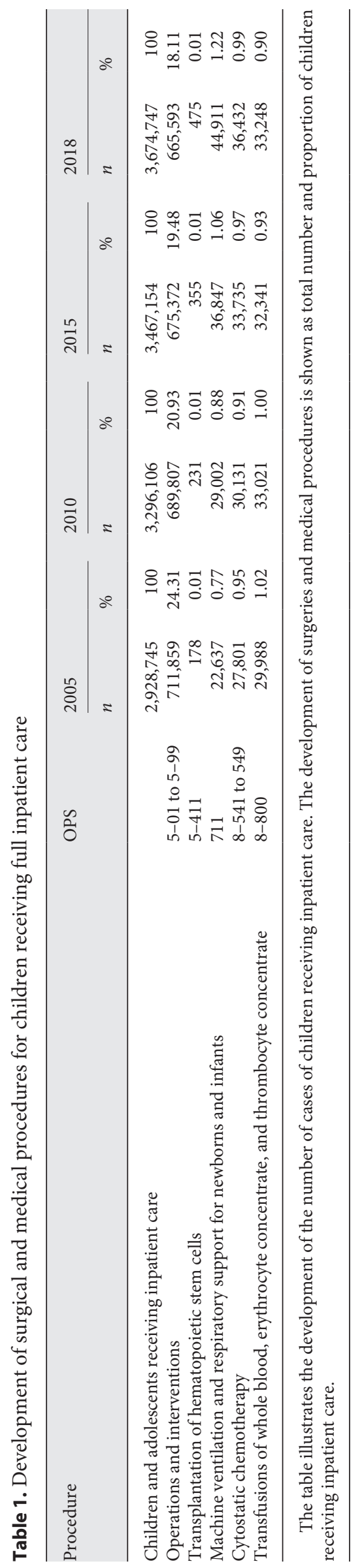

\section{Transfusion-Associated Procedures}

In the area of evaluated medical indications, cytostatic chemotherapy, immunotherapy, and antiretroviral therapy (OPS 8-541 to 549) showed a $31 \%$ increase in coded cases, from 27,801 (2005) to 36,432 (2018). The largest increase was in children $<1$ year of age, up to $183 \%$ - from 740 to 1,830 coded cases. Hematopoietic stem cell transplantation (OPS 5-411) was coded 475 times in 2018 and 178 times in 2005 (Table 1). An increase of $167 \%$ could be observed. Machine ventilation and respiratory support for neonates and infants (OPS 711) were recorded in $0.77 \%$ of infants cared for in hospital in 2005 and $1.22 \%$ in 2018. A decrease of $6.5 \%$ from 711,859 (2005) to 665,993 (2018) for surgical interventions (OPS 5-01 to 5-99) in Germany for children aged 1-17 years was shown. For the age groups $<1$ year of age and $1-4$ years of age, the number of operations increased by $4 \%(63,741-$ $66,347)$ and $8 \%(155,572-168,783)$ from 2005 to 2008. The largest number of operations per inhabitant aged $0-17$ years could be found in the federal state of Hamburg with $9.76 \%$. Finally, Schleswig-Holstein had the lowest percentage of operated children at $3.51 \%$.

\section{Discussion}

Transfusion rates for children and adolescents receiving inpatient care have been declining in recent years. In $2018,0.9 \%$ of all children received inpatient care, and $0.2 \%$ of all children in Germany received at least one transfusion. In comparison, $6.6 \%$ of the adults who have undergone surgery receive transfusion with red cell concentrate [1]. The transfusion rates for adults also declined from 2005 to 2017 , with a $15 \%$ annual reduction in the number of red cell concentrates used, from 4,580 to 3,890 transfusion units per 100,000 inhabitants [1]. However, we were able to demonstrate increases in transfusion rates in the subgroups aged 1-4 year and 5-10 years. The data on transfusion-associated procedures analyzed in parallel should provide indications of possible causes of this development. Based on data from a study in England, which described the proportional distribution of indications for transfusions, medical and surgical procedures were considered as examples [12]. Children between the ages of 5 and 14 were transfused primarily for medical reasons, as were children between 0 and 4 and adolescents between 15 and 19 years of age, but the latter also presented with surgical indications [12]. In the procedures considered as examples, such as chemotherapy or ventilation of newborns and infants as an indirect indicator of respiratory distress syndrome, we were able to demonstrate both absolute and relative increases, so no direct explanation for the decline in transfusion rates could be found. One explanatory approach may be the introduction of various 
measures to save blood products and the cautious indication for transfusion of blood products. To reduce the probability of perioperative transfusions, for example, the Patient Blood Management (PBM) program, was initiated in Germany in 2013 [8-10]. Although the PBM was primarily introduced in the area of adult care, its individual measures may also have had an impact on pediatrics. The treatment of iron deficiency anemia with iron preparations or the use of erythropoietin; reduction of the number and volume of blood samples; and adherence to physiological conditions of hemostasis $(\mathrm{pH}$, calcium concentration and temperature) can be used, as well as the use of bedside coagulation diagnostics and targeted therapy in children [2, 13-15, 16-24].

\section{Regional Differences}

An explanation for regional differences could not be deduced from the data. Possible causes may be different coding behavior, different specialized hospital density, and regional differences in the frequency and severity of traffic accidents involving children. A comparison with the distribution in surgically treated adult patients with transfusion rates ranging from $6.1 \%$ in Bavaria to $7.7 \%$ in Mecklenburg-Vorpommern revealed that, as expected, the transfusion frequency in children was lower [1].

\section{Transfusion Indication}

Children and adolescents, and especially neonates and infants, differ significantly from adults, both anatomically and physiologically. These differences must be taken into account when deciding on a transfusion. The current guidelines provide information on the indication for transfusion in children [25]. For children over 4 months of age, the current cross-sectional guideline of the German Medical Association recommends, for example, limits of $<8.2 \mathrm{~g} / \mathrm{dL}$ for preoperative anemia and $<10.2 \mathrm{~g} / \mathrm{dL}$ for acute blood loss and simultaneous instability [25]. The current recommendation of the European Anaesthesia Society (ESA) includes $\mathrm{Hb}$ limits of 7-9 g/dL [26]. For premature infants, neonates, and infants, age-dependent hematocrit limits between $<25$ and $<40$, as well as clinical indication parameters such as ventilation or life-threatening symptoms due to hypovolemia, are defined or aimed for as limits [25]. In principle, a study in the pediatric intensive care unit for children could not demonstrate a higher risk of complications or mortality from a restrictive transfusion strategy with a transfusion trigger of $7 \mathrm{~g} / \mathrm{dL}$ [17]. In any case, the sole consideration of hemoglobin concentration should not be used to determine the indication for transfusion. Rather, it is necessary to consider physiological triggers, such as global indicators of insufficient oxygen supply (e.g., lactic acidosis, drop in mixed venous $\mathrm{O}_{2}$ saturation) and cardiopulmonary symptoms (e.g., tachycardia, hypotension) [27].

\section{Limitations}

The transfusion data available through the Federal Statistical Office do not contain any information on the transfused volume and do not differentiate between whole blood, platelet, and erythrocyte concentrates. However, no whole blood preparations are currently used in Germany. The proportion of platelet concentrates is included in the total transfusion volume given. For a detailed analysis, the complete OPS beyond the 4th digit would be necessary. A filtering of the results according to medical areas (conservative vs. operative medicine) is not possible with the available data set. The reason for this is the data delivery of the hospitals in the form of a report with content such as OPS 8-800 1,500×. The individual patient cases in which one could assign operative and conservative medicine - i.e., which contain the combined information of OPS 8-800 and OPS 5-01 to 5-99 - are not passed on.

\section{Conclusion}

The analysis of existing DRG data from the Federal Statistical Office provide a good overview of the development of transfusion frequency in Germany among children and adolescents. For the collective as a whole, a relative decline in transfusion rates was seen for the entire observation period. Regional differences for transfusion and surgical care were observed but may also be caused by confounders. For children between 1 and 10 years, however, an increase in transfusions in the range of $0.04-0.09 \%$ was recorded. Measures to reduce transfusions are therefore also recommended in the treatment of children. Prospective studies to evaluate transfusion triggers in children, differentiated according to different age cohorts, are urgently needed.

\section{Acknowledgement}

We thank the Federal Statistical Office of Germany for providing the data requested.

\section{Statement of Ethics}

The databases of the Federal Statistical Office are collected routinely and are intended for scientific evaluation and do not allow conclusions to be drawn about individual persons. An ethics approval was therefore not necessary.

\section{Conflict of Interest Statement}

F.P. received honoraria from Pharmacosmos for scientific lectures. P.M. and K.Z. received grants from B. Braun Melsungen, CSL Behring, Fresenius Kabi, and Vifor Pharma for the implementation of Frankfurt's Patient Blood Management program and honoraria for scientific lectures from B. Braun Melsungen, Vifor 
Pharma, Ferring, CSL Behring, and Pharmacosmos. A.S. is supported by the German Research Foundation (Deutsche Forschungsgemeinschaft) grant STE 1895/4-2 and Innovative Medical Research (Innovative Medizinische Forschung) grants IMF 121617, IMF 221810, and IMF 211901 of the Medical Faculty, University of Münster, Münster, Germany. A.S. is also sponsored by a research grant from Pharmacosmos, Denmark, to perform a single-center, prospective trial on preoperative anemia treatment. There are no other conflicts of interest to disclose.

\section{Funding Sources}

This study was supported by internal institutional research funds of the Department of Anaesthesiology, Intensive Care and Pain Therapy, University Hospital Frankfurt, Goethe University, Frankfurt, Germany.

\section{Author Contributions}

F.P. helped with substantial contributions to the conception and design of the work; the acquisition, analysis, and interpretation of the data for the work; drafting the work; and writing the manuscript. A.S. helped with substantial contributions to the conception and design of the work; the acquisition, analysis, and interpretation of the data for the work; drafting the work; and writing the manuscript. K.Z. helped with substantial contributions to the conception and design of the work; the acquisition, analysis, and interpretation of the data for the work; drafting the work; and writing the manuscript. P.M. helped with substantial contributions to the conception and design of the work; the acquisition, analysis, and interpretation of the data for the work; drafting the work; and writing the manuscript.

\section{References}

1 Augurzky Boris DS, Hentschker C, Mensen A. Krankenhausreport 2019, Patient BloodManagement. Schriftenreihe zur Gesundheitsanalyse; 2019.

2 Parker RI. Transfusion in critically ill children: indications, risks, and challenges. Crit Care Med. 2014 Mar;42(3):675-90.

3 Lavoie J. Blood transfusion risks and alternative strategies in pediatric patients. Paediatr Anaesth. 2011 Jan;21(1):14-24.

4 Howard-Quijano K, Schwarzenberger JC, Scovotti JC, Alejos A, Ngo J, Gornbein J, et al. Increased red blood cell transfusions are associated with worsening outcomes in pediatric heart transplant patients. Anesth Analg. 2013 Jun;116(6):1295-308.

5 Stainsby D, Jones H, Wells AW, Gibson B, Cohen H; SHOT Steering Group. Adverse outcomes of blood transfusion in children analysis of UK reports to the serious hazards of transfusion scheme 1996-2005. Br J Haematol. 2008 Apr;141(1):73-9.

6 Oakley FD, Woods M, Arnold S, Young PP. Transfusion reactions in pediatric compared with adult patients: a look at rate, reaction type, and associated products. Transfusion. 2015 Mar;55(3):563-70.

7 Vossoughi S, Perez G, Whitaker BI, Fung MK, Stotler B. Analysis of pediatric adverse reactions to transfusions. Transfusion. 2018 Jan; 58(1):60-9.

8 Statistisches Bundesamt DeStatis. Krankenhausdiagnosestatistik. Gesundheitsberichterstattungdes Bundes; 2019.

9 Baierlein J, Leibinger P, Zacharowski K, Meybohm P. Approaches to health care research usingpublicly available routine data-chances and limitations of hospital coded transfusions (OPS code 8-800*) in Germany. Anästh Intensivmed. 2019;60:506-19.

10 Baierlein J, Leibinger P, Zacharowski K, Meybohm P. Wie wir stationäre Routinedaten im Rahmender Versorgungsforschung nutzen können. Gesundheitsökonomie \& Qualitätsmanagement; 2019. https://doi.org/10.1055/ a-0863-9322.
11 Statistisches Bundesamt DeStatis. Fallpauschalenbezogene Krankenhausstatistik. 2017

12 Wells AW, Mounter PJ, Chapman CE, Stainsby D, Wallis JP. Where does blood go? Prospective observational study of red cell transfusion in north England. BMJ. 2002 Oct; 325(7368):803

13 Meybohm P, Schmitz-Rixen T, Steinbicker A, Schwenk W, Zacharowski K. [The patient blood management concept : Joint recommendation of the German Society of Anaesthesiology and Intensive Care Medicine and the German Society of Surgery]. Chirurg. 2017 Oct;88(10):867-70.

14 Oswald E, Stalzer B, Heitz E, Weiss M, Schmugge M, Strasak A, et al. Thromboelastometry (ROTEM) in children: age-related reference ranges and correlations with standard coagulation tests. Br J Anaesth. 2010 Dec;105(6):827-35.

15 Vogel AM, Radwan ZA, Cox CS Jr, Cotton BA. Admission rapid thrombelastography delivers real-time "actionable" data in pediatric trauma. J Pediatr Surg. 2013 Jun;48(6): 1371-6.

16 Istaphanous GK, Wheeler DS, Lisco SJ, Shander A. Red blood cell transfusion in critically ill children: a narrative review. Pediatr Crit Care Med. 2011 Mar;12(2):174-83.

17 Lacroix J, Hébert PC, Hutchison JS, Hume HA, Tucci M, Ducruet T, et al.; TRIPICU Investigators; Canadian Critical Care Trials Group; Pediatric Acute Lung Injury and Sepsis Investigators Network. Transfusion strategies for patients in pediatric intensive care units. N Engl J Med. 2007 Apr;356(16):1609-19.

18 Pérez-Ferrer A, Gredilla-Díaz E, de VicenteSánchez J, Sánchez Pérez-Grueso F, GilsanzRodríguez F. Implementation of a patient blood management program in pediatric scoliosis surgery. Rev Esp Anestesiol Reanim. 2016 Feb;63(2):69-77.

19 Nguyen TT, Hill S, Austin TM, Whitney GM, Wellons JC 3rd, Lam HV. Use of blood-sparing surgical techniques and transfusion algorithms: association with decreased blood ad- ministration in children undergoing primary open craniosynostosis repair. J Neurosurg Pediatr. 2015 Nov; 16(5):556-63.

20 Naguib AN, Winch PD, Tobias JD, Simsic J, Hersey D, Nicol K, et al. A single-center strategy to minimize blood transfusion in neonates and children undergoing cardiac surgery. Paediatr Anaesth. 2015 May;25(5):477-86.

21 Nguyen TT, Lam HV, Phillips M, Edwards C, Austin TM. Intraoperative optimization to decrease postoperative PRBC transfusion in children undergoing craniofacial reconstruction. Paediatr Anaesth. 2015 Mar;25(3):294300 .

22 Vega RA, Lyon C, Kierce JF, Tye GW, Ritter AM, Rhodes JL. Minimizing transfusion requirements for children undergoing craniosynostosis repair: the CHoR protocol. J Neurosurg Pediatr. 2014 Aug;14(2):190-5.

23 Wittenmeier E, Goeters C, Becke K. [Patient blood management: does the approach also make sense in children?]. Anasthesiol Intensivmed Notfallmed Schmerzther. 2016 May; 51(5):296-306.

24 Goobie SM, Gallagher T, Gross I, Shander A. Society for the advancement of blood managementadministrative and clinical standards for patient blood management programs. 4th edition(pediatric version). Paediatr Anaesth. 2019Mar;29(3):231-6.

25 Bundesärztekammer WB. QuerschnittsLeitlinien zur Therapie mit Blutkomponenten undPlasmaderivaten-Herausgegeben von der Bundesärztekammer auf Empfehlung ihresWissenschaftlichen Beirats. 4. überarbeitete Auflage. Köln: Deutscher Ärzte-Verlag; 2014.

26 Kozek-Langenecker SA, Ahmed AB, Afshari A, Albaladejo P, Aldecoa C, Barauskas G, et al. Management of severe perioperative bleeding: guidelines from the European Society of Anaesthesiology: First update 2016. Eur J Anaesthesiol. 2017 Jun;34(6):332-95.

27 Welte M, Zacharowski K. Der individualisierte Transfusionstrigger. Anästh Intensivmed. 2018;59:132-44. 